\title{
Patterned Co-culture of Live Cells on a Microchip by Photocrosslinking with Benzophenone
}

\author{
Kiichi SATo, ${ }^{* \dagger}$ Sayaka KIKUCHI,* Eri YoshIDA,** Reina ISHII,** Naoki SASAKI,** \\ Kin-ichi TsunODA, ${ }^{*}$ and Kae SATO** \\ *Department of Chemistry and Chemical Biology, School of Science and Technology, Gunma University, \\ Kiryu, Gunma 376-8515, Japan \\ **Department of Chemical and Biological Sciences, Faculty of Science, Japan Women's University, Bunkyo, \\ Tokyo 112-8681, Japan
}

\begin{abstract}
The patterned coculture of different types of living cells in a microfluidic device is crucial for the analysis of cellular interactions and cell-cell communication. In the present study, cell patterning was achieved by photocrosslinking benzophenone derivatives in a microfluidic channel. Optimization of UV irradiation conditions enabled successful fixation of live cells. In addition, patterning and co-culture of non-adherent K562 cells and adherent RF-6A cells was achieved by successive rounds of patterning. The present approach is expected to be useful for the development of in vitro methods for studying cell signaling.
\end{abstract}

Keywords Benzophenone, cell fixation, microfluidic device, adherent cells, non-adherent cells, photocrosslinking reaction

(Received September 24, 2015; Accepted October 12, 2015; Published January 10, 2016)

\section{Introduction}

Microchips are highly useful for single cell analyses ${ }^{1}$ that require the use of expensive reagents such as antibodies and enzymes. ${ }^{2,3}$ As such, microchip-based cell analyses, the subject of widespread attention, have been applied to the study of mammalian cells. Mammalian cells are categorized as adherent or non-adherent. Adherent cells attach onto a bottom surface of a microchannel spontaneously, whereas non-adherent cells lack this ability. For manipulation or analysis of non-adherent cells, it is necessary to fix the cells onto the channel surface. Although the Cytospin method, which involves centrifugation onto glass slides, is used to fix non-adherent cells to microscope slides or coverslips, ${ }^{4}$ this method cannot be applied to the microchip format. Therefore, chemical bonding is necessary to fix non-adherent cells to a microchip.

Methods involving the use of polycarbonate membranes ${ }^{5}$ and dam structures ${ }^{6}$ have been utilized for microchip-based analyses of non-adherent cells. Although methods for fixation of nonadherent cells onto chemically modified surfaces have been reported, they were not microchip-based. For example, Yamaguchi et al. described a cell fixation method using a cell membrane binding reagent consisting of polyethylene glycol and an oleyl group, ${ }^{7}$ and our group reported a method involving photocrosslinking with a benzophenone (BP) derivative. ${ }^{8}$ As photochemical reactions may be controlled by UV light, our

† To whom correspondence should be addressed.

E-mail: kiichi.sato@gunma-u.ac.jp

N. S. present address: Department of Applied Chemistry, Faculty of Science and Engineering, Toyo University, Kawagoe, Saitama 350-8585, Japan. previously reported method may be utilized in the closed space of the microchannel.

$\mathrm{BP}$, a well-known photoresponsive molecule, forms covalent bonds with a wide range of biomolecules, ${ }^{9}$ and is easily immobilized onto the surface of a glass substrate using standard silane coupling agents. BP-modified substrates have been utilized to immobilize DNA ${ }^{10-12}$ and proteins. ${ }^{10,13,14}$ Our previous study is the only report of the direct fixation of non-adherent cells onto glass substrates using BP. ${ }^{8}$

The BP-based photocrosslinking method is suitable not only for fixation of non-adherent cells but also for patterning and co-culture of various types of cells. Co-culture of different cell types may trigger the expression of native cell function. Patterning and co-culture of different kinds of cells inside a microchannel is useful, not only for investigation of direct cell-cell communication through gap junctions, but also for studying paracrine cell-cell communication, as the effects of upstream-released soluble molecules on downstream cells may be controlled by regulating flow culture conditions. In order to achieve co-culture, live cells must be fixed to obtain good cell growth post-fixation.

Several co-culture studies, such as a liver tissue model using HepG2 and fibroblast cells, ${ }^{15,16}$ as well as a culture of embryonic stem cells using mouse embryonic fibroblast cells as feeder cells ${ }^{17}$ have been reported. Recently, Rothbauer et al. reported a microfluidic co-culture system based on laminar flow-patterned protein nanolayers. ${ }^{18}$ In this laminar flow-based method, flexibility of the pattern was limited. For example, because different kinds of cells cannot be placed upstream and downstream of the channel, the effects of soluble molecules released from cells on the other cells are not controllable. On the other hand, cell patterning using optical irradiation has wider flexibility in designing the pattern, because photomask 
can be designed freely and precisely.

In the present study, cell fixation was performed via a BP-based photocrosslinking reaction. UV irradiation conditions were optimized to fix live cells. In addition, patterning and co-culture of two different cell types in a microchannel was achieved.

\section{Experimental}

\section{Chip fabrication}

A polydimethylsiloxane (PDMS)-glass slide modified with a BP hybrid device was fabricated, as described previously, with small modifications. ${ }^{8}$ Briefly, a cover slip was immersed in $3 \%$ 3-aminopropyltriethoxysilane (APS) in ethanol and incubated for $3 \mathrm{~h}$ at $70^{\circ} \mathrm{C}$. The APS solution was then removed from the case, which was incubated for a further $1 \mathrm{~h}$ at $70^{\circ} \mathrm{C}$. The cover slip was bonded to a PDMS sheet with a through-hole $(5 \mathrm{~mm}$ diameter, $2 \mathrm{~mm}$ depth) to form an open-well on the substrate. An aliquot $(20 \mu \mathrm{L})$ of a solution containing $0.2 \mathrm{M}$ benzophenone4-isothiocyanate and $0.05 \mathrm{M}$ diisopropylethylamine in dimethylformamide (DMF) was poured into the well. Then, the well was incubated for $72 \mathrm{~h}$ at room temperature. Next, the PDMS sheet was peeled off the cover slip, which was rinsed with DMF, dried, and bonded to a PDMS sheet with a microchannel $(800 \mu \mathrm{m} \times 1 \mathrm{~mm} \times 10 \mathrm{~mm})$ or well $(5 \mathrm{~mm}$ diameter, $2 \mathrm{~mm}$ depth).

\section{Cell staining}

For CellTracker Green, Orange, or Red staining, cell suspension was incubated with $10 \mu \mathrm{M}$ CellTracker dye (Invitrogen, Carlsbad, CA) in a culture media without serum for $30 \mathrm{~min}$ at $37^{\circ} \mathrm{C}$. Cells were centrifuged and the CellTracker working solution was removed. The culture media was then added to obtain a suspension.

\section{Cell patterning}

A suspension of human K562 erythroleukemia (non-adherent cells) cells or Rhesus monkey RF-6A cells (adherent cells) was prepared at a concentration of $3 \times 10^{7}$ cells $/ \mathrm{mL}$ in phosphatebuffered saline (PBS). An aliquot $(20 \mu \mathrm{L})$ of the suspension was introduced into the channel and incubated for $1 \mathrm{~min}$ at room temperature. The channel was then irradiated with UV light passed through a photomask $(500 \mu \mathrm{m}$ stripe pattern $)$ under an inverted microscope (IX71, Olympus, Tokyo, Japan) equipped with a $100-\mathrm{W}$ high-pressure mercury lamp, $4 \times$ or $10 \times$ objective lens, and a dichroic mirror block (U-MWU2, Olympus). The channel was then rinsed with PBS.

\section{Live/dead assay}

Live/dead assay was performed with calcein-AM (Dojindo, Kumamoto, Japan) and propidium iodide (Sigma-Aldrich, St. Louis, MO). A solution containing $2 \mu \mathrm{M}$ calcein AM (greenfluorescent) to indicate intracellular esterase activity, and $4 \mu \mathrm{M}$ propidium iodide (red-fluorescent) to indicate loss of plasma membrane integrity was introduced into the cellpatterned channel, and incubated for $30 \mathrm{~min}$ at $37^{\circ} \mathrm{C}$ and $5 \%$ $\mathrm{CO}_{2}$.

NucView 488 caspase-3 assay kit (Biotium, CA, USA) was used for the apoptosis assay. A solution containing $5 \mu \mathrm{M}$ NucView 488 caspase-3 substrate in binding buffer was placed on a glass substrate with cells, and incubated for $30 \mathrm{~min}$ at $37^{\circ} \mathrm{C}$ and $5 \% \mathrm{CO}_{2}$. The nuclei of apoptotic cells were stained green.

Cells were visualized using a fluorescence microscope IX71 with a dichroic mirror block (U-MWIBA3 and U-MWIG3,
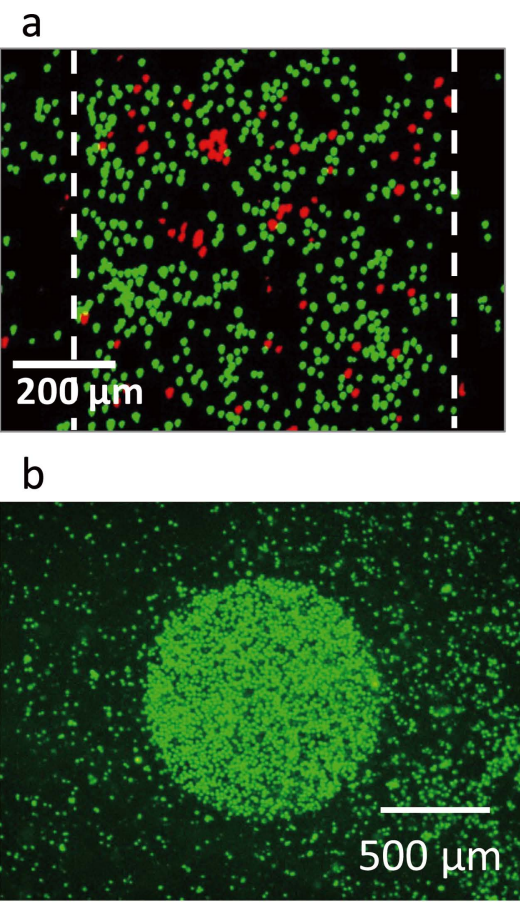

C

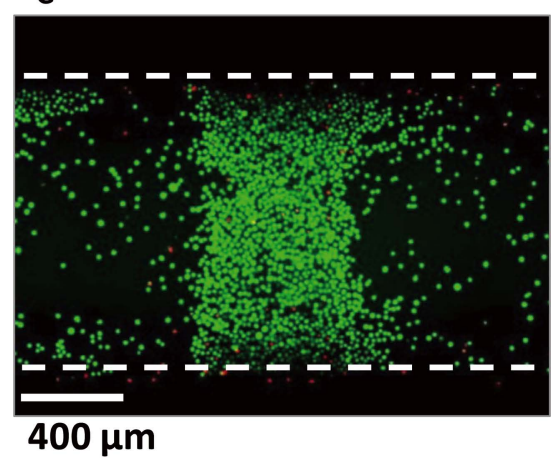

Fig. 1 Effects of irradiation conditions. a) K562 cells were patterned inside the microchannel using a $10 \times$ objective lens with UV irradiation for $2 \mathrm{~min}$. The image was acquired after the live/dead assay. Dead cells are visualized as red. b) Results of the caspase- 3 assay. Cells were patterned in the well using a $10 \times$ objective lens with UV irradiation for $5 \mathrm{~min}$, and a circle-shaped photomask. Staining of nuclei indicates apoptosis. c) Cells were patterned inside the microchannel using a $4 \times$ objective lens with UV irradiation for $4 \mathrm{~min}$. Most cells were alive after patterning.

Olympus; for cells stained with green and orange or red dye, respectively).

\section{Results and Discussion}

\section{Conditions of UV irradiation}

In our previous work, cell patterning with diameter of $1.0 \mathrm{~mm}$ or $0.5 \mathrm{~mm}$ was realized using an IX71 microscope equipped with a $10 \times$ objective lens (UPLFLN10XPH, Olympus), a 100-W mercury lamp, and an ND25 filter. ${ }^{8}$ Cells were patterned using UV light exposure at a fluence of over $1 \mathrm{~J} / \mathrm{mm}^{2}$. K562 cells were patterned into a stripe shape in a microchannel under similar conditions (Fig. 1a).

Results of live/dead assay of the patterned cells indicated that some cells were killed by UV irradiation. The nuclei of the patterned cells were found to be stained following caspase- 3 


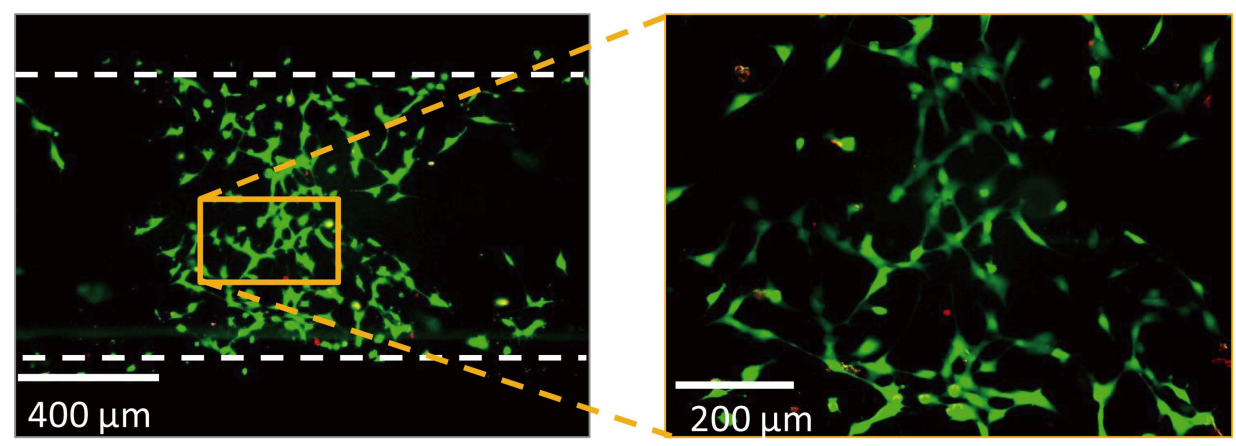

Fig. 2 Patterned RF-6A cells after $24 \mathrm{~h}$ of culture. The image was acquired after the live/dead assay was performed.

a

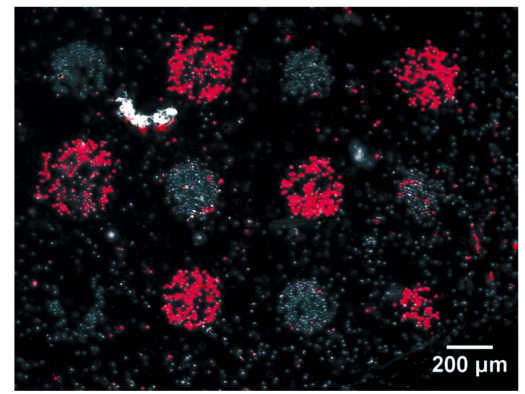

b

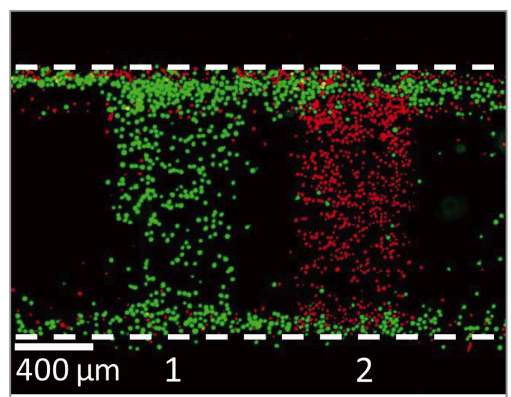

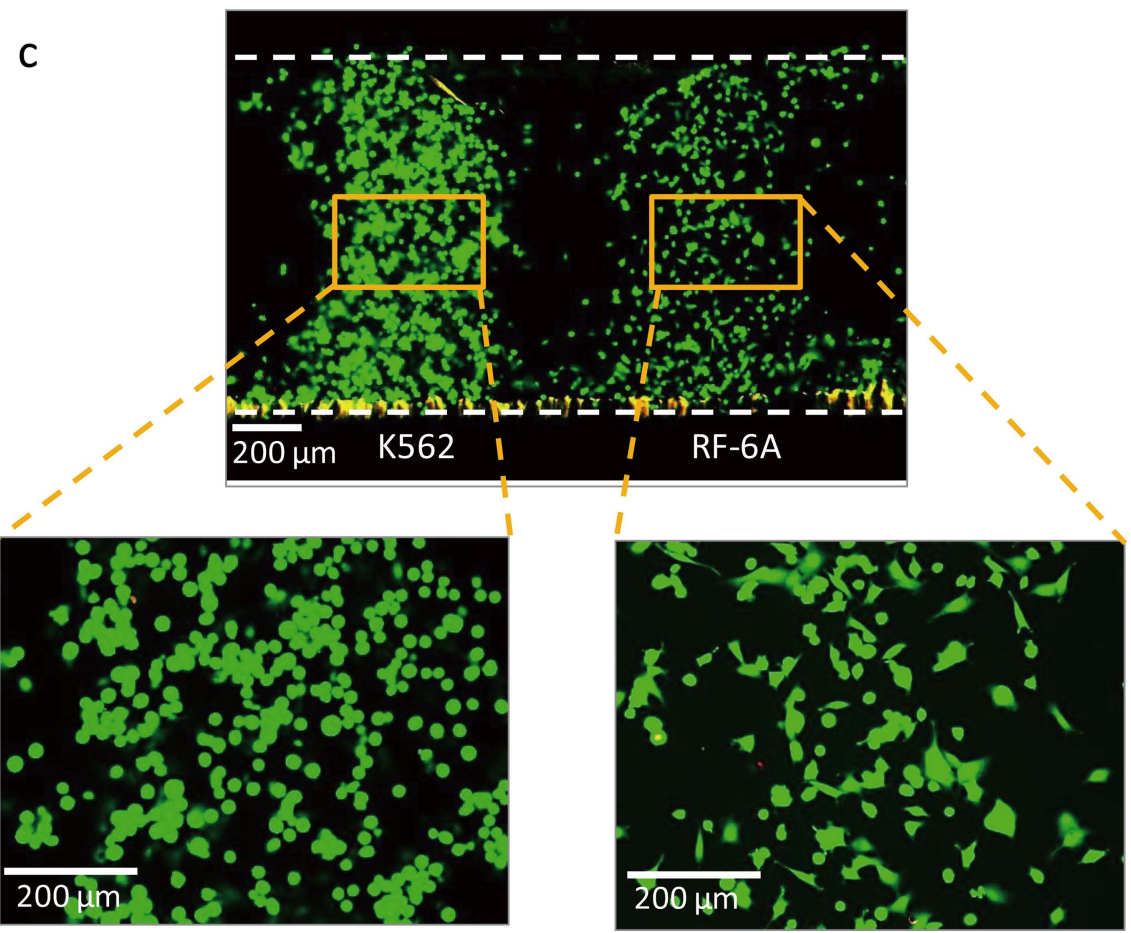

Fig. 3 Double patterning. a) Composite of the fluorescent and phase-contrast images of K562 cells patterned in a circular shape. The cells patterned first were stained red. b) Fluorescent image of K562 cells patterned inside the microchannel. Cells stained in green were patterned first, and cells stained orange were patterned second. c) Results of live/dead assay of patterned cells; K562 cells were patterned first, and RF-6A cells were patterned second.

assay, confirming that the death of the cells was caused by apoptosis (Fig. 1b).

Patterning conditions were examined for live cell patterning. A high rate of cell death was observed when the $10 \times$ objective lens was used; however, most of the patterned cells were found to be alive when the $4 \times$ objective lens was used with an irradiation time of $4 \mathrm{~min}$ (Fig. 1c and Table S1 (Supporting Information)). 


\section{Patterned cell culture}

The patterned cells were cultured in a microchannel. After culturing for $24 \mathrm{~h}$, both non-adherent K562 cells and adherent RF-6A cells were found to be alive. In addition, attachment and stretching was observed in the RF-6A cells (Fig. 2).

\section{Double patterning}

Cells were patterned onto areas neighboring the sites of previously patterned cells by a second round of photopatterning. A suspension of K562 cells prestained with CellTracker Red was added to a well. UV light was irradiated through a photomask with micropores of $0.2 \mathrm{~mm}$, at $0.3 \mathrm{~mm}$ intervals. Then, the well was gently washed with PBS. The photomask was repositioned slightly, and non-stained K562 cells were patterned by the same procedure (Fig. 3a). Composites of fluorescent and phase-contrast images showed that the cells patterned in the first round were retained after the second patterning procedure, and that successive rounds of patterning on the surface of the same well had been achieved.

The above process was repeated in a microchannel. A suspension of K562 cells prestained with CellTracker Green was introduced into the microchannel. UV light was irradiated through a photomask with a $0.2-\mathrm{mm}$ stripe pattern. Then, the channel was gently washed with PBS. The photomask was repositioned slightly, and K562 cells prestained with CellTracker Orange were patterned using the same procedure (Fig. 3b). Composite fluorescent images showed that successive rounds of patterning of the two cell types had been achieved in the microchannel.

Patterning of heterogeneous cells was performed in the microchannel. K562 cells were patterned first, followed by RF-6A cells (Fig. 3c). Results of live/dead assay of the patterned cells showed that most of the patterned cells were alive. After $24 \mathrm{~h}$ of co-culture, patterned K562 cells were found to be spherical in shape, and RF-6A cells were observed to be stretched.

\section{Conclusions}

Cell patterning inside a microchannel was achieved via BP-based photocrosslinking. UV irradiation conditions were optimized to enable cells to be successfully fixed alive. In addition, double patterning and co-culture of non-adherent K562 cells and adherent RF-6A cells was performed.

The present approach is expected to be highly useful for the analysis of cell-cell signaling via paracrine communication and through gap junctions, thereby enabling the development of in vitro methods for the study of cellular interactions in health and disease.

\section{Acknowledgements}

This work was supported in part by the NEDO Industrial Technology Research Assistance Project, Shimadzu Science
Foundation, Asahi Glass Foundation, and a Grant-in-Aid for Scientific Research (JSPS, KAKENHI; Grant Numbers 15K15199, 24350035, and 15H03823).

\section{Supporting Information}

Relation between cell patterning conditions and survival rates of the cells. This material is available free of charge on the Web at http://www.jsac.or.jp/analsci/.

\section{References}

1. C. H. Lin, Y. H. Hsiao, H. C. Chang, C. F. Yeh, C. K. He, E. M. Salm, C. Chen, I. M. Chiu, and C. H. Hsu, Lab Chip, 2015, 15, 2928.

2. A. Kuroda, Y. Ishigaki, M. Nilsson, and K. Sato, Anal. Sci., 2014, 30, 1107.

3. M. Blazek, T. S. Santisteban, R. Zengerle, and M. Meier, Lab Chip, 2015, 15, 726.

4. C. M. Koh, Methods Enzymol., 2013, 533, 235.

5. P. Shah, I. Vedarethinam, D. Kwasny, L. Andresen, M Dimaki, S. Skov, and W. E. Svendsen, Sens. Actuators, B, 2011, 156, 1002.

6. H. Yamazoe, Y. Sugiyama, A. El Omri, Y. Hagihara, and T. Okada, J. Biosci. Bioeng., 2014, 117, 375.

7. S. Yamaguchi, S. Yamahira, K. Kikuchi, K. Sumaru, T. Kanamori, and T. Nagamune, Angew. Chem., Int. Ed., 2012, $51,128$.

8. N. Sasaki, A. Isu, R. Ishii, and K. Sato, Anal. Sci., 2012, 28 , 537.

9. G. Dorman and G. D. Prestwich, Biochemistry, 1994, 33, 5661.

10. M. Y. Balakirev, S. Porte, M. Vernaz-Gris, M. Berger, J. P. Arie, B. Fouque, and F. Chatelain, Anal. Chem., 2005, 77, 5474.

11. B. Renberg, K. Sato, K. Mawatari, N. Idota, T. Tsukahara, and T. Kitamori, Lab Chip, 2009, 9, 1517.

12. Y. Tanaka, H. Xi, K. Sato, K. Mawatari, B. Renberg, M. Nilsson, and T. Kitamori, Anal. Chem., 2011, 83, 3352.

13. K. Shirai, B. Renberg, K. Sato, K. Mawatari, T. Konno, K. Ishihara, and T. Kitamori, Electrophoresis, 2009, 30, 4251.

14. T. A. Martin, C. T. Herman, F. T. Limpoco, M. C. Michael, G. K. Potts, and R. C. Bailey, ACS Appl. Mater. Interfaces, 2011, 3, 3762.

15. S. N. Bhatia, U. J. Balis, M. L. Yarmush, and M. Toner, Biotechnol. Prog., 1998, 14, 378.

16. H. J. Lee and W. G. Koh, ACS Appl. Mater. Interfaces, 2014, 6, 9338

17. A. Khademhosseini, L. Ferreira, J. Blumling, 3rd, J. Yeh, J. M. Karp, J. Fukuda, and R. Langer, Biomaterials, 2006, 27, 5968.

18. M. Rothbauer, P. Ertl, B. A. Theiler, M. Schlager, U. B. Sleytr, and S. Kupcu, Adv. Mater. Interfaces, 2015, 2, 1400309. 